\title{
Periodontal Disease on Pregnant Women (Case Study: Pondok Labu Village, South Jakarta, Indonesia)
}

\author{
Rikawarastuti, Ngatemi, Nita Noviani Harahap \\ Department of Dental Nursing, Health Polytechnic Jakarta I, Ministry of Health, Indonesia
}

\begin{tabular}{l}
\hline \hline Article Info \\
\hline Article history: \\
Received Mar 8, 2016 \\
Revised Apr 28, 2016 \\
Accepted May 18, 2016 \\
\hline
\end{tabular}

\section{Keyword:}

Knowledge

Oral hygiene

Periodontal disease

Pregnant woman

\begin{abstract}
During preganancy, women periodically concern about ANC due to fetus growth, but ignore their own periodontal health. This research was conducted to acknowledge the effect of age, educational background, parity, body mass index (BMI), diabetes mellitus, smoking habit and oral hygiene with periodontal disease on pregnant women. Analytical observation study with cross sectional design was conducted to pregnant women in Pondok Labu Village (Kelurahan), South Jakarta. Purposive sampling was performed among 101 respondents. Chi Square and logistic regression were used for the analysis. Results shown that periodontal disease on pregnant women were $73.2 \%$ (66.3\% were calculus and $6.9 \%$ were having periodontal pocket of $4-5$ $\mathrm{mm})$. It is proven that there is relationship between age, educational background, parity, BMI, diabetes mellitus, and smoking habit to the periodontal disease. On the other hand, oral hygiene highly affected the periodontal disease on pregnant woman. Poor oral hygiene is the dominant factor of periodontal disease on pregnant women after being controlled by age $(\mathrm{OR}=21.33$, $\mathrm{p}$ value 0.005$)$. It is advised for pregnant women to improve their knowledge on how to care for their oral hygiene prior to and during pregnancy, as well as, go through treatments with dentists.
\end{abstract}

Copyright (C) 2016 Institute of Advanced Engineering and Science. All rights reserved.

\section{Corresponding Author:}

Rikawarastuti, Department of Dental Nursing,

Health Polytechnic Jakarta I, Ministry of Health ,

Jl. Wijayakusuma Raya no. 47, Cilandak, Jakarta Selatan, Indonesia.

Email: rikawarastuti@gmail.com

\section{INTRODUCTION}

Pregnancy is a challenging physiological and emotional experience for a woman. The majority of pregnant women, for the sake of good health of the child to be born as well as because of material benefits guaranteed for pregnant women by welfare system, scrupulously attend scheduled medical examinations [1]. Pregnancy is an important milestone in the life-course of a female with the dual factors of pregnancy affecting oral health and oral health affecting the pregnancy outcome. During pregnancy, hormones alter immunoresponsiveness and inflammatory response mediators. This has been reported to cause oral problems, primarily gingivitis and periodontal infection [2]. Pregnant women are vulnerable to common oral diseases such as periodontal disease and dental caries; if oral hygiene is not well maintained during this period, there are implications for oral hygiene in her subsequent life [3]. Nevertheless, pregnant women are more focused on antenatal care of the development of her fetus than their dental hygiene and periodontal health condition.

Periodontitis is a chronic inflammatory disease of the tissues that support the teeth. Periodontal disease is a common oral infection with prevalence ranging from 10-60\% and refers to gingivitis and periodontitis [4]. Exposure to risk factors, such as age, low socio-economic status, poor education, HIV infection, low dental care utilization, poor oral hygiene level, smoking habit, parity (i.e. number of children born) and psycho social stress tend to arise in certain populations. These factors are more, or as important, as race and ethnicity [5]. A recent study of pregnant women in Brazil revealed a $47 \%$ prevalence of periodontal 
disease, indicating a strong need for the initiation of oral care during early pregnancy. The prevalence of periodontal disease (PD) among Brazilian low-risk pregnant women and its association with sociodemographic factors, habits and oral hygiene shows a high prevalence of periodontal disease and it is associated with gingival bleeding on probing, more advanced gestational age and obesity. A program of oral hygiene should be included in prenatal care for early pregnancy, especially for low-income populations [6].

Researched maternal periodontal disease in the maternity unit of Hospital das Clínicas, Federal University of Pernambuco, in the city of Recife, in the northeastern region of Brazil showed that periodontitis is an important risk factor for prematurity, independent of other factors. To establish this as a scientific fact, we believe that randomized studies are needed, in order to have a greater degree of certainty in ascertaining the impact of treatment for periodontitis during pregnancy, with regard to reducing prematurity [7].

Given the impact of periodontal disease of pregnant women to the baby to be born, it is necessary to know the factors associated with maternal periodontal disease. Therefore, the present study aims to obtain the factors associated with maternal periodontal disease in Pondok Labu Village (Kelurahan), South Jakarta, Indonesia.

\section{RESEARCH METHOD}

\subsection{Data Collection}

The population of this research is every pregnant woman in Pondok Labu Village, South Jakarta, Indonesia and the samples are some pregnant women who visited the health center (integrated health center, community health center) in Pondok Labu Village. The data collection of pregnant women in Pondok Labu Village has been approved by the Head of Pondok Labu Village. The sampling used purposive sampling method on pregnant women who undertook routine antenatal care (ANC) starting from June to September 2015. The samples taken were women consistent with the inclusion criteria of pregnant women aged $\geq 20$ years old, who have filled out informed consent form, with teeth needed for measurement and no history in radiation therapy, meanwhile, the exclusion criteria are pregnant women aged $<20$ years old and unwilling to participate as the subject of this research. The minimum quantity of sample is 93 pregnant women, but for this research, the minimum quantity of sample taken was 100 pregnant women. After conducting the research, there were 104 pregnant women, but only 101 women with complete interview and CPITN examination, therefore, these 101 pregnant women are chosen as data samples.

The researchers did a periodontal tissue examination with a maximum time of 10 minutes for each respondent, using tools and materials, such as, dental tweezer, dental mirror, WHO periodontal probe, disclosing solution and alcohol. The results of the examination are recorded in dental examination sheets. The data characteristic of the respondents were collected during interviews and recorded in questionnaires.

\subsection{Variables}

This research aims to obtain prevalence on pregnant women periodontal disease and its relation with independent variables, such as, age, educational background, parity, body mass index, diabetes mellitus, smoking habit and dental and oral hygiene, meanwhile, the dependent variable is periodontal disease status.

Dental and oral hygiene is measured with OHI-S score, which is a composite index between Debris Index (DI) and Calculus Index (CI). The OHI-S score used is based on Greene and Vermilion categories $(0.0$ -1.2 = good; $1.3-3.0=$ fair; $3.1-6.0=$ poor $)$.

The periodontal tissue of the pregnant women was examined using CPITN score and at the same time, it was used to probe the periodontal care needs of the pregnant women. The WHO CPITN scores are: 0 (healthy), 1 (bleeding), 2 (calculus), 3 (periodontal pocket $\geq 4-5 \mathrm{~mm}$ ), and 4 (periodontal pocket $\geq 6 \mathrm{~mm}$ ). CPITN score for 0 means healthy and there is no need for any treatment, 1 interprets bleeding and there is a requirement for the improvement of personal oral hygiene, 2 interprets calculus and there is a requirement for scaling and an improvement in oral hygiene, 3 interprets periodontal pocket $\geq 4-5 \mathrm{~mm}$ which requires for scaling and an improvement in oral hygiene and 4 interprets periodontal pocket $\geq 6 \mathrm{~mm}$ which requires for a more complex treatment. The periodontal disease status of the respondent is determined by a second category from CPITN score; non PD (Periodontal Disease) with CPITN score of $0-1$, and PD if CPITN score $\geq 2$.

\subsection{Data Analysis}

IBM SPSS Statistic for Windows (version 17.0) was used for data processing. The characteristics of the respondents were calculated using descriptive statistics, including frequencies and percentages. Bivariate analysis was conducted to observe the relationship between each independent variable (age, educational background, parity, body mass index, diabetes mellitus, smoking habit and dental and oral hygiene) with dependent variable (periodontal disease status). The bivariate analysis was conducted with a simple logistic regression for variables with measurement result of more than 2 categories and chi square, specifically for 
variable measurement result of 2 categories. Analysis was conducted to identify $\mathrm{p}$ value and risk factors (odd ratio) of each independent variable.

The multivariate analysis conducted was logistic regression analysis. The logistic regression was selected because the dependent variable in this research, periodontal disease status, is dichotomous (PD and non PD).

\section{RESULTS AND ANALYSIS}

\subsection{Characteristic of Pregnant Women based on Age, Educational Background, Parity}

The characteristic of the pregnant women based on age, educational background and parity can be observed in Table 1 . Table 1 shows that the quantity of pregnant women $\geq 35$ years old were lesser $(25.7 \%)$ when compared to pregnant women aged $<35$ years old $(74.3 \%)$ because pregnant women who routinely visited health facilities (integrated health post, community health center) in Pondok Labu Village were dominated by young mothers.

Table1. Characteristic of pregnant women based on age, educational background and parity

\begin{tabular}{llc}
\hline \multicolumn{1}{c}{ Variable } & n & Total \\
\hline Age $\quad$ & 75 & \\
$\quad<35$ yo & 26 & 74.3 \\
$\quad \geq 35$ yo & & 25.7 \\
Educational Background & 76 & 74.3 \\
$\quad$ Low Educational Background & 25 & 25.7 \\
$\quad$ High Educational Background & & \\
Parity & 66 & 65.3 \\
$\quad 0-1$ & 35 & 34.7 \\
\hline 2
\end{tabular}

The majority of the pregnant women had low educational background (elementary school to high school) for as much as $74.3 \%$ and those with a high educational background (academy or university) were $25.7 \%$. Mothers with low educational background prefer to go to midwives in their nearest Integrated Health Post or Community Health Center for their antenatal care because it is near and cheaper, meanwhile, pregnant women with high educational background have more opportunities to visit the hospital or private clinic because they can afford it. There are respondents with children and others are their first pregnancy. Nullipara and primipara pregnant women were $65.3 \%$ and multipara women were $34.7 \%$. Such data indicates a successful birth control program or family with quality in Pondok Labu Village.

\subsection{Characteristic of Pregnant Women based on Body Mass Index, Diabetes Mellitus, Smoking Habit and Dental and Oral Hygiene}

The characteristic of pregnant women based on body mass index, diabetes mellitus, smoking habit and dental and oral hygiene can be observed in Table 2.

Table 2. Characteristic of pregnant women based on body mass index, diabetes mellitus, smoking habit and dental and oral hygiene

\begin{tabular}{cccc}
\hline \multicolumn{1}{c}{ Variable } & n & Total \\
\hline BMI & \multicolumn{2}{c}{} \\
\hline$<18.5$ & 6 & 5.9 \\
$18.5-22.9$ & 25 & 24.8 \\
$>=23$ & 70 & 69.3 \\
Sytemic Disease & & \\
$\quad$ DM & 2 & 2 \\
$\quad$ Non DM & 99 & 98 \\
Smoking Habit & & \\
$\quad$ Non Smoker & 2 & 2 \\
$\quad$ Smoker & 99 & 98 \\
Dental and Oral Hygiene & & \\
$\quad$ 0.0-1.2 (good) & 28 & 27.7 \\
1.3-3.0 (fair) & 56 & 55.4 \\
3.1-6.0 (poor) & 17 & 16.8 \\
\hline & &
\end{tabular}

IJPHS Vol. 5, No. 2, June 2016: 170-175 
Table 2 describes that $69.3 \%$ of pregnant woman has BMI over 23 which can be categorized as overweight. This is common because pregnant women gain weight. Pregnant women with index $<18.5$ were $5.9 \%$ because they were in their first timester. Respondents with a smoking habit were 2 and there were 2 with diabetes mellitus. The OHI-S index of the respondents with fair dental and oral hygiene was $55.4 \%$, with good dental and oral hygiene $27.7 \%$ and with poor dental and oral hygiene $16.8 \%$ respondents.

\subsection{Periodontal Disease and Dental Care for Pregnant Women}

The need for dental care was measured using CPITN score and can be observed in Table 3. Table 3 shows that need for dental care of pregnant women in Pondok Labu Village, $21.8 \%$ respondents were declared healthy and did not need any treatment, $5 \%$ of the respondents were bleeding and need improvements in personal oral hygiene, $66.3 \%$ of the respondents had calculus and need scaling and improvements in oral hygiene, and $6.9 \%$ of the respondents had periodontal pocket $\geq 4-5 \mathrm{~mm}$ and scaling and improvements in oral hygiene are needed. The periodontal disease status of the respondents can be observed in Table 4.

Table 3. CPITN score of the pregnant women

\begin{tabular}{lcc}
\hline \multicolumn{1}{c}{ CPITN Score } & n & Total \\
\hline 0 (healthy) & 22 & \% \\
1 (bleeding) & 5 & 21.8 \\
2 (calculus) & 67 & 6.0 \\
3 (periodontal poket $\geq 4-5 \mathrm{~mm}$ ) & 7 & 6.9 \\
4 (periodontal pocket $\geq 6 \mathrm{~mm}$ ) & 0 & 0 \\
\hline
\end{tabular}

Table 4. Periodontal disease status of the pregnant women

\begin{tabular}{ccc}
\hline Variable & n & Total \\
\hline Periodontal Disease & & \\
Non PD & 27 & 26.8 \\
PD & 74 & 73.2 \\
\hline
\end{tabular}

The prevalence of peridontal disease of pregnant women in Pondok Labu Village is $73.2 \%$. The prevalence of periodontal disease of pregnant women in this research is high (73.2\%) as was found in healthcare centers in the central and eastern regions of Saudi Arabia due to limited knowledge and awareness on periodontal disease and its effects on pregnancy among pregnant women [8].

\subsection{Analysis of Relationship}

Analysis of relationship between variables of age, educational background, parity, body mass index, diabetes mellitus, smoking habit and dental and oral hygiene can be observed in Table 5. Table 5 shows there are no significant relationships statistically between age, educational background, parity, body mass index, diabetes mellitus and smoking habit with periodontal disease, meanwhile, the variable with significant relationship statistically is dental dan oral hygiene ( $\mathrm{p}$ value $<0.05$ ).

Periodontal disease is characterised by destruction of the periodontal ligament, bone and soft tissue as a result of a local host immune response to microbial plaque on the tooth surface. If left untreated, this inflammation leads to alveolar bone resorption and, eventually, tooth loss The severity of the disease is modified by genetics, host response and lifestyle factors such as oral healthcare, smoking, age, race, hormonal changes, obesity, and diabetes [9].

From the result of this research, it is concluded that poor dental and oral hygiene can increase the risk of periodontal disease status. The result is in accordance with the research conducted in Brazil which concluded that poor dental and oral hygiene is related to periodontal disease with average value of index on dental plaque and bleeding on probing was significantly higher in periodontal disease group [6]. The result of the research in Brazil is in accordance with the research on pregnant women in Antenatal Clinic (AnC) of Lagos State University Teaching Hospital (LASUTH), Ikeja, Lagoswhich shows a significant relationship between periodontal disease status with CPI and OHI-S score variables [10]. 
Table 5. The relationship between the characteristic of the respondents and periodontal disease status

\begin{tabular}{|c|c|c|c|c|c|c|}
\hline \multirow{3}{*}{ Variable } & \multicolumn{4}{|c|}{ Periodontal Disease Status } & \multirow{3}{*}{$95 \% \mathrm{CI}$} & \multirow{3}{*}{$P$ value } \\
\hline & \multicolumn{2}{|c|}{ Non PD } & \multicolumn{2}{|c|}{ PD } & & \\
\hline & $\mathrm{n}$ & $\%$ & $\mathrm{~N}$ & $\%$ & & \\
\hline \multicolumn{7}{|l|}{ Age } \\
\hline$<35$ yo & 17 & 22.7 & 58 & 77.3 & $0.180-1.222$ & 0.190 \\
\hline$\geq 35$ yo & 10 & 38.5 & 16 & 61.5 & & \\
\hline \multicolumn{7}{|l|}{ Educational Background } \\
\hline Low Educational Background & 17 & 22.4 & 59 & 77.6 & $0.165-1.134$ & 0.142 \\
\hline High Educational Background & 10 & 40.0 & 15 & 60.0 & & \\
\hline \multicolumn{7}{|l|}{ Parity } \\
\hline $0-1$ & 20 & 30.3 & 46 & 69.7 & $0.652-4.637$ & 0.380 \\
\hline$\geq 2$ & 7 & 20.0 & 28 & 80.8 & & \\
\hline \multicolumn{7}{|l|}{ BMI } \\
\hline$<18.5$ & 1 & 16.7 & 5 & 83.3 & $0.189-15.823$ & 1.731 \\
\hline $18.5-22.9$ & 8 & 32.0 & 17 & 68.0 & $0.271-1.993$ & 0.271 \\
\hline$>=23$ & 18 & 25.7 & 52 & 74.3 & & \\
\hline \multicolumn{7}{|l|}{ Systemic Disease } \\
\hline Non DM & 27 & 27.3 & 72 & 72.7 & $0.645-0.821$ & 0.955 \\
\hline DM & 0 & 0 & 2 & 100 & & \\
\hline \multicolumn{7}{|l|}{ Smoking Habit } \\
\hline Non Smoker & 27 & 27.3 & 72 & 72.7 & $0.645-0.821$ & 0.955 \\
\hline Smoker & 0 & 0 & 2 & 100 & & \\
\hline \multicolumn{7}{|l|}{ Dental and Oral Hygiene } \\
\hline $0.0-1.2($ good $)$ & 16 & 57.1 & 12 & 42.9 & & \\
\hline $1.3-3.0$ (fair) & 10 & 17.9 & 46 & 82.1 & $2.225-16.904$ & $0.005^{*}$ \\
\hline $3.1-6.0$ (poor) & 27 & 26.7 & 74 & 73.3 & $2.474-183.965$ & $0.005^{*}$ \\
\hline
\end{tabular}

The main factor of periodontal disease in pregnant women can be observed in Table 6 . The poor dental and oral hygiene is the main factor of periodontal disease because the risk of suffering from periodontal disease is 21.33 times higher ( $p$ value 0.005 ) after being controlled by the age variable. The poor dental and oral hygiene can be triggered by the complex physiological alteration in pregnant women, such as, nausea and vomiting, up to a change in diet and poor oral hygiene. Oral health during pregnancy is important in order to minimize possible undesirable perinatal results and to improve the quality of life and wellbeing of the expectant mother and her baby. A program of oral health care should be developed and implemented for early pregnancy and should provide information on oral hygiene and periodontal treatment during prenatal care, particularly among women at greater risk [6]. Whereas, pregnancy is an important milestone in a woman's life and it suggests for an increased need for dental care, among other healthcare needs [3].

Table 6. Main factor of periodontal disease in pregnant women

\begin{tabular}{lcc}
\hline \multicolumn{1}{c}{ Variable } & OR $(95 \% \mathrm{CI})$ & P value \\
\hline Age & $2.634(0.880-7.885)$ & 0.083 \\
Dental and Oral Hygiene (1) & $6.752(2.357-19.340)$ & $0.000^{*}$ \\
(2) & $23.283(2.621-206.834)$ & $0.005^{*}$ \\
\hline
\end{tabular}

\section{CONCLUSION}

The prevalence in periodontal disease on pregnant women in Pondok Labu Village is of high and significantly related with dental and oral hygiene. Poor dental and oral hygiene is the main factor of periodontal disease in pregnant women after being controlled by age variable. Pregnant women are advised to improve the knowledge and skill in dental and oral hygiene prior to and during pregnancy, go through treatments with dentists and encourage healthcare staff to give education on dental and oral hygiene for pregnant women.

\section{ACKNOWLEDGEMENTS}

We would like to thank Head of Departement of Dental Nursing, Health Polytechnic Jakarta I, Ministry of Health, for the support of this research. Infinite gratitude awarded to pregnant women in Pondok Labu Village (Kelurahan) who had participated in the study. The research was funded by the Health Polytechnic Jakarta I, Ministry of Health, the Republic of Indonesia, 2015. 


\section{REFERENCES}

[1] E. Gaszyńska, et al., "Dental awareness and oral health of pregnant women in Poland," Int. J. Occup. Med. Environ. Health, vol/issue: 28(3), pp. 603-11, 2015.

[2] M. N. Wandera, et al., "Periodontal status, tooth loss and self-reported periodontal problems effects on oral impacts on daily performances, OIDP, in pregnant women in Uganda: a cross-sectional study," Health Qual. Life Outcomes, vol. 7, pp. 89-99, 2009.

[3] N. Karunachandra, et al., "Reply to comment on: oral health status during pregnancy: rural-urban comparisons of oral disease burden among antenatal women in Sri Lanka," Rural Remote Health, vol/issue: 12(3), pp. 2348, 2012.

[4] X. Xiong, et al., "Periodontal disease and adverse pregnancy outcomes: a systematic review," BJOG An Int. J. Obstet. Gynaecol, vol/issue: 113(2), pp. 135-143, 2006.

[5] M. Wandera, et al., "Socio-demographic factors related to periodontal status and tooth loss of pregnant women in Mbale district, Uganda," BMC Oral Health, vol/issue: 9(1), pp. 18-29, 2009.

[6] M. Vogt, et al., "Factors associated with the prevalence of periodontal disease in low-risk pregnant women," Reprod. Health, vol/issue: 9(1), pp. 3-11, 2012.

[7] M. D. B. V Piscoya, et al., "Maternal periodontitis as a risk factor for prematurity," Pediatr. Int., vol/issue: 54(1), pp. 68-75, 2012.

[8] F. A. Asa'ad, et al., "Periodontal disease awareness among pregnant women in the central and eastern regions of Saudi Arabia.," J. Investig. Clin. Dent., vol/issue: 6(1), pp. 8-15, 2015.

[9] B. P. Veselinovic, et al., "Changes in inflammatory mediators in gingival crevicular fluid following periodontal disease treatment in pregnancy: relationship to adverse pregnancy outcome," J. Reprod. Immunol., vol. 112, pp. 1$10,2015$.

[10] O. O. Onigbinde, et al., "Periodontal Status and Some Variables among Pregnant Women in a Nigeria Tertiary Institution," Ann. Med. Health Sci. Res., vol/issue: 4(6), pp. 852-857, 2014.

\section{BIOGRAPHIES OF AUTHORS}

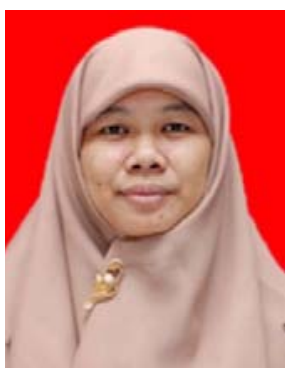

Name: Rikawarastuti

Email: rikawarastuti@gmail.com

Educational Background:

1. Master Degree in Public Health Science, Universitas Indonesia, 2003

2. Bachelor Degree in Public Health, Universitas Indonesia, 2001

Organization and Working Experiences:

1. Lecturer in Poltekkes Jakarta I, 2011 up to now

2. Member of IAKMI, 2014 up to now

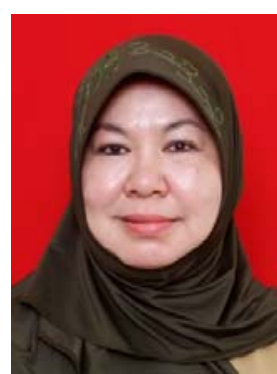

Name: drg. Nita Noviani Harahap, MKM

Email: nita.noviani@yahoo.com

Educational Background:

1. Bachelor Degree in Dentistry, Universitas Trisakti, 1988

2. Master Degree in Health Promotion and Behavioral Sciences, Universitas Indonesia, 2010 Organization and Working Experiences:

1. Lecturer in Poltekkes Jakarta I, 1989 up to now

2. Member of PDGI, 1989 up to now

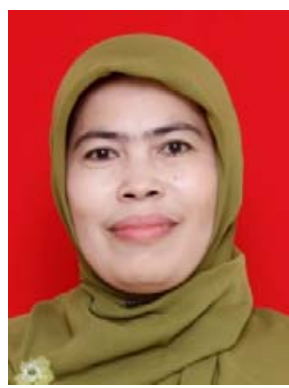

Name: Ngatemi, S.SiT, MKM

Email: Ngatemi02@yahoo.com

Educational Background:

1. Diploma in Dentistry, Universitas Gajah Mada, 2002

2. Master Degree in Public Health Service Quality, 2012

Organization and Working Experiences:

1. Lecturer in Poltekkes Jakarta I, 2011 up to now

2. Member of PPGI, 1987 up to now 